\title{
Extrusion of cement-based materials - an overview
}

\author{
Arnaud Perrot $^{\mathrm{a}^{*}}$, Damien Rangeard ${ }^{\mathrm{b}}$, Venkatesh Naidu Nerella ${ }^{\mathrm{c}}$, Viktor Mechtcherine ${ }^{\mathrm{c}}$ \\ a Univ. Bretagne Sud, UMR CNRS 6027, IRDL, F-56100 Lorient, France \\ b INSA Rennes, EA 3913, LGCGM, F- 35000 Rennes, France \\ c Technische Universität Dresden, Institute of Construction Materials, 01062 Dresden, Germany
}

Received: 27 December 2018 / Accepted: 28 January 2019 / Published online: 13 February 2019

(C) The Author(s) 2019. This article is published with open access and licensed under a Creative Commons Attribution 4.0 International License.

\begin{abstract}
Extrusion is a process which consists in forcing a formable material to pass through a die having the cross-section of the part to be obtained. This way of processing is used with both conventional and fibre-reinforced cement-based materials to fabricate various construction elements such as panels, pipes, and roadside kerbs. Recently, with the development of digital fabrication methods and, especially, 3D concrete printing by selective deposition, extrusion techniques have aroused a significant increase in interest.

This study describes screw and ram extrusion techniques and their applications in the construction industry. Furthermore, the underlying mechanisms which are part of extrusion flow are delineated, and the roles of rheological and hydro-mechanical behaviour, the latter in a context of soil mechanics, in defining the extrudability of the cementitious materials are highlighted. Finally, specific points such as flow-induced anisotropy of fibre-reinforced cementitious materials or surface defects are addressed.
\end{abstract}

Keywords: Cement-based materials; Rheology; Tribology; Extrusion; 3D Printing

\section{Introduction}

Extrusion is a common manufacturing process used in many industrial sectors. When utilizing mineral materials in the construction industry, the process is widely used to form fired, unfired or stabilized clay bricks at a highly productive rate. However, the application of extrusion to concrete and other cementitious materials has been mostly limited to specific cases, such as roadside kerbs or slender elements made of high-performance engineering composites [1, 2].

However, with the emergence of digital concrete construction techniques, the extrusion of cement-based materials has recently gained close interest [3-7]. One of the most widely followed digital construction methods is based on extrusion and is generally referred to as 3D-concreteprinting.

Due to its relatively infrequent use, the extrusion of cementbased materials has not been studied extensively; moreover, the theoretical knowledge is mainly based on ceramics extrusion [8]. Clay and cement-based materials possess some similarities, e.g., they both behave as visco-plastic materials and exhibit non-Newtonian behaviour in respect of yieldstress. However, these two groups of materials also exhibit some critical differences, mainly resulting from the size and shape of their particles. Cement-based materials are more sensitive to water drainage, in a sense that they are prone to exhibit a behaviour similar to that of granular materials, unlike platelet-shaped clay particles, which makes them difficult to extrude $[9,10]$. The article at hand presents a state-of-the-art review on the extrusion of cement-based materials with a special focus on their flow characteristics and rheological properties.

One important aspect with respect to the extrusion of cement-based materials is the definition of the term itself. This "engineering" characteristic is commonly associated with the ability of the concrete to remain homogeneous during flow, meaning that no water drainage occurs during extrusion. The soil mechanics theory, based on Terzaghi's consolidation theory, is often used to describe such fluid drainage during extrusion [11].

In 3D-printing applications the extrudability of cementitious materials plays a decisive role. On one hand, systematically optimised mixtures are needed to ensure a consistent extrusion process over long time periods allowing for periodic interruptions for such things as tool head re-positioning. On the other hand, the extrudability of a cement-based material impacts the extrusion flowrate and, thus, the geometry, density, and other properties of 3D-printed elements.

Several further specific points can be related to the extrusion of cement-based materials. Among them the effect of

\footnotetext{
* Corresponding author: Arnaud Perrot, E-mail: arnaud.perrot@univ-ubs.fr
} 
extrusion flow on the orientation of fibres is probably the most important and most straightforward as well [12]. Accordingly, the importance of surface condition and finish quality is addressed here.

\section{Use of extrusion in concrete industry}

\subsection{Technology of concrete extrusion}

\subsubsection{Ram extrusion}

In ram extrusion, the material located inside the extruder barrel is pushed by a ram, which has the same cross-section as the barrel, toward a gradually narrowing or abruptly constricted die, which imposes its shape on the material.

Ram extrusion is not a conventional way to process materials on an industrial scale since it is not a continuous process; as such it requires periodic refilling of the barrel. However, ram extrusion is often used on a laboratory scale in order to study extrusion flow, describe rheological behaviour, and assess the extrudability of various materials [12-15]. Extrusion flow is used to estimate the flow properties of stiff cement-based materials whose rheological and tribological behaviour could not be evaluated using rotational rheometers [16]. Despite their having been already applied to cement-based materials, these methods and techniques have been inspired by the literature on ceramics, especially the works of Benbow and Bridgewater [8]. Different ram extruder designs allow studying the load necessary to change the cross-section of cement-based materials $[12,18]$ or to measure the friction acting at the extruder wall $[13,19]$; see Figure 1.

\subsubsection{Screw extrusion}

Screw extrusion is the most common extrusion technique, in which the material is continuously fed into the extruder barrel, wherein an Archimedes screw is used to convey it toward the die [20]; see Figure 2a. When using an adequate feeding system, it allows for highly productive processing method on an industrial or semi-industrial scale; see Figure $2 b$
$[21,22]$. Screw extruders are also used at a laboratory scale to test the material extrudability and for related mixture optimization; see Figure 2c [23].

The inside surface of the extruder is provided with a longitudinal groove in order to orient the material flow along the extruder screw and toward the die. A vacuum de-airing system is often added in order to reduce the entrapped air content and thus increasing material density and strength and durability as well. It should be noted here that progressive cavity pumps have been used in the context of concrete 3Dprinting in order to stabilise extrusion flow; see Figure $2 \mathrm{~d}$ ).

\subsubsection{Measures to enhance extrusion flow}

As discussed in the introduction shape-stable, cement-based materials are very sensitive to water drainage, which makes them difficult to extrude. In order to address this issue and to reduce the permeability of the cement matrix, viscositymodifying admixtures and ultrafine substances such as nanoclay and silica fume are often added to cement-based materials designed for extrusion purposes [15, 24-26].

Alternatively, various techniques have been used to ease flow by reducing extrusion force and the friction at the material/extruder interface. The first technique is to apply the difference in electric potential between screw and barrel in order to promote the formation of a lubricating layer at the barrel/screw interface $[27,28]$. The second approach is to generate vibration in the die area in order to reduce the apparent friction locally and the plastic stress in the die land [29]. This latter solution has been shown to allow the processing of mixtures with high aggregate content and with no viscosity-modifying admixtures. a

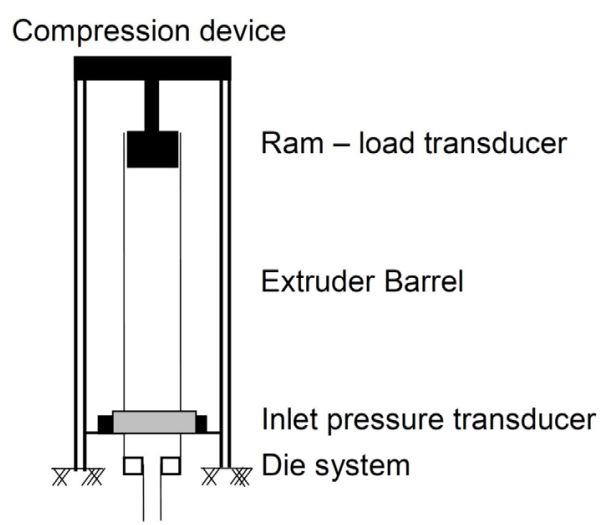

b

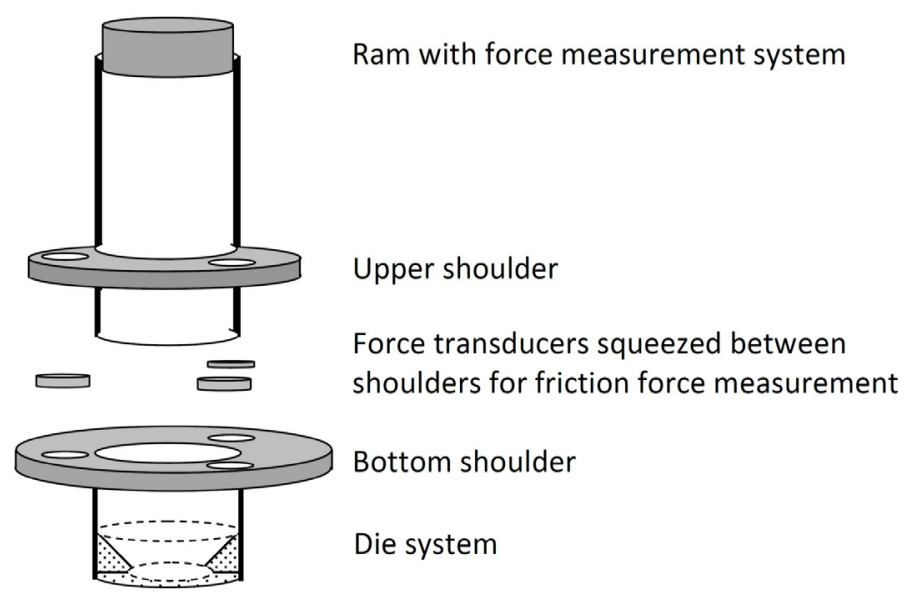

Figure 1. Ram extruder test setups with a) inlet pressure measurement as in [12], b) friction force measurement as in [13]. 


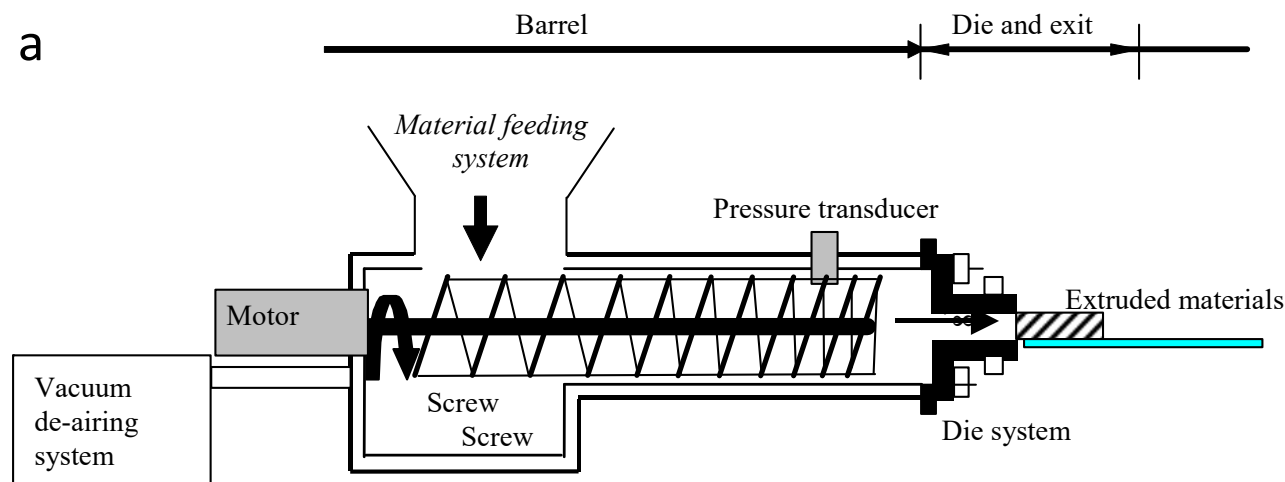

b

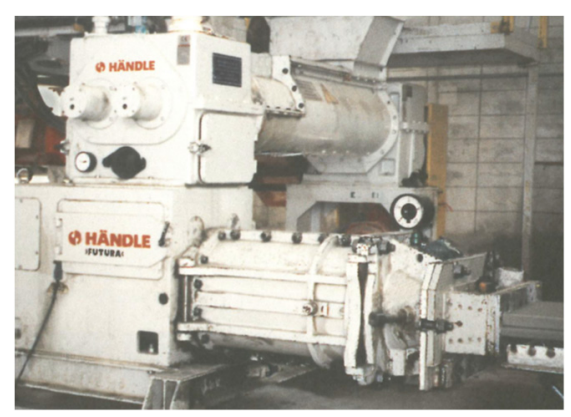

C

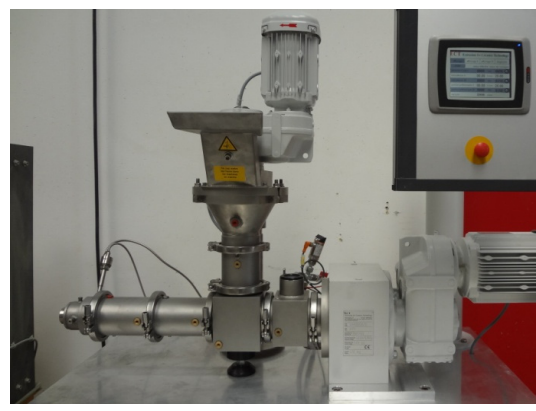

d

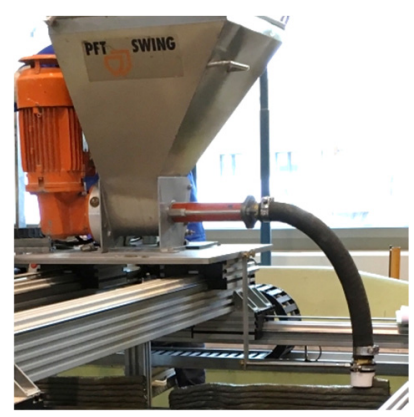

Figure 2. a) Schematic of a screw extrusion process, b) industrial screw-extruder, c) lab-scale screw extruder and d) screw-extruder on printhead of a 3D-printer.

\subsection{Use of extrusion for concrete products}

\subsubsection{Conventional use}

The extrusion of cement based-materials may be considered as a marginal manufacturing process used for specific applications in the precast industry. Fireboards [25], panel walls [21, 22], pipes [30] or high tensile strength, fibrereinforced elements [31, 32] have been fabricated by extrusion. Another application of concrete extrusion is the processing of roadside kerbs and safety barriers [1]. However, this application is often considered to be a variant of a slipforming process rather than a conventional extrusion.

\subsubsection{D-printing applications}

Extrusion-based 3D-printing methods are probably the most highly developed techniques in digital concrete construction [4, 5, 7, 33, 34]. Roussel [5] pointed out that extrusion-based concrete 3D-printing methods can be divided in two families: 1) the material is fluid and cannot hold its shape upon deposition; 2) the material is able to withstand gravity, as a so-called "infinite brick". Only the second family can be considered for conventional extrusion because such a processing route implies the shape-stability of the deposited material.

In an alternative perspective, Nerella et al. argued that in digital construction, extrudability and shape-stability should be treated separately. The authors argued that the shapestability of superimposed extruded layers is typically accounted for in the so-called buildability of printable, cement-based materials.

\section{Extrusion flow of cement-based materials \\ 3.1 Flow description for ram extrusion}

In order to study material flow during the extrusion process, the case of axisymmetric ram extrusion is often considered as the reference case because of its simplicity and its availability in the academic and industrial worlds. Extrudable mineral suspensions and, specifically, cementitious materials exhibit a visco-plastic behaviour, which can be described by the Bingham or Herschel-Bulkley models, with a high yield stress needed for shape stability. As shown by non-destructive or destructive testing, the ram-extrusion flow of the cementitious materials can always be divided into three parts [35-37]; see Figure 3:

- plug flow in the extruder barrel;

- conical "dead" zone where the material remains immobile around the die entry (In an optimally designed progressive die, the dead zone would not exist);

- "shaping" zone located inside the conical dead zone or inside the progressive die, where material forming takes place and the billet diameter decreases to that of the orifice.

Each of these parts contributes to the total extrusion force according to Figure 3 by: 
- the wall friction force $F_{f r}$ along the extruder barrel; $F_{f r}$ linearly decreases with the reduction of the contact surface between material and barrel;

- the forming force $F_{p l}$ required for the plastic alteration of the material's geometry and achieving its final shape in the die land.

At the exit of the die, an end channel with constant crosssection can exist and induce additional friction resistance.

a

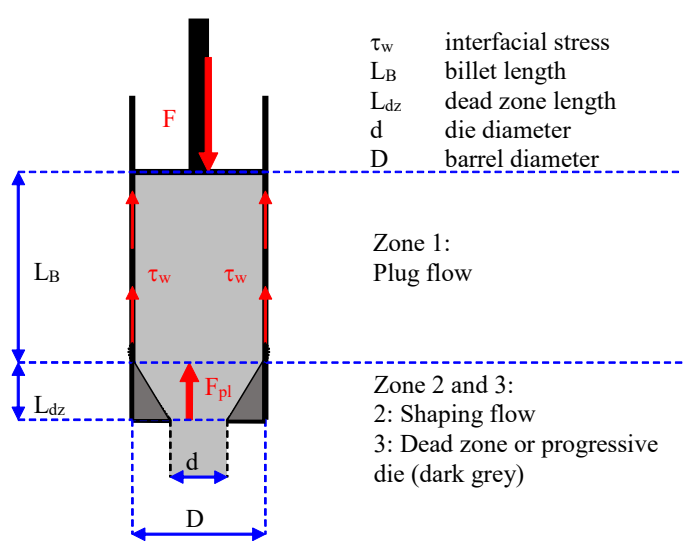

b

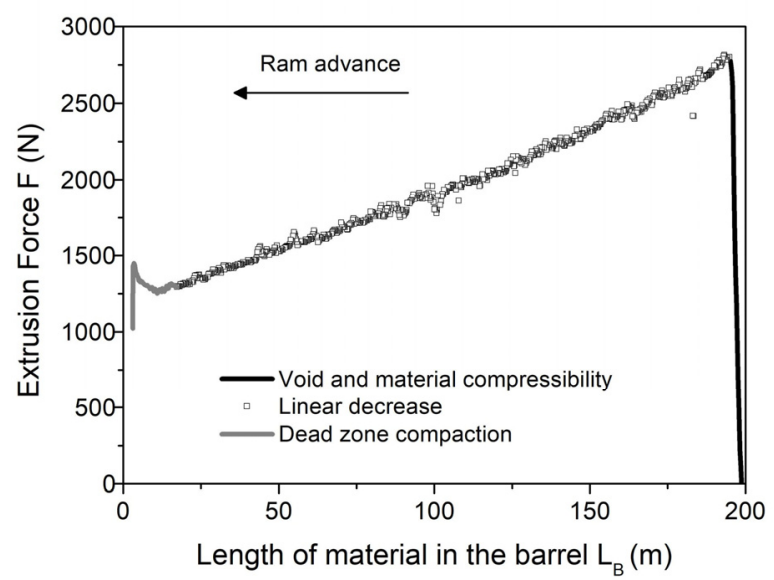

Figure 3. a) Schematic view of an axisymmetric ram extrusion flow and b) evolution of extrusion force $F$ with length of material remaining in the plug flow zone.

\subsection{Flow in the shaping zone}

For abrupt contraction, the length of the shaping zone has been shown to be approximately the same as the length of the dead zone and is equal to $0.5(D-d)[13]$.

In the shaping zone, the contraction induces an elongational flow that plastically deforms the cementitious visco-plastic material. Only a few studies have focused specifically on cement-based materials, but there are some numerical and experimental works aiming to describe the flow of viscoplastic materials in this zone [36-40]. For high Binghamnumber fluids, their velocity increases as the material gets closer to the orifice as the barrel contracts. Just after flowing past the contraction, the material velocity becomes constant [36], as shown in Figure 4.
The model formulation for the forming force $F_{p l}$ has been the subject of numerous studies. The reference work of Benbow and Bridgwater [8], based on the computation of the energy needed to reduce the material from $D$ to $d$ by plastic deformation, has been used successfully to describe the flow of cementitious materials [12, 14, 41, 42]. This equation reads:

$$
F_{p l}=\frac{\pi D^{2}}{2} \cdot\left(\sigma_{0}+\alpha V^{n_{B B}}\right) \ln \left(\frac{D}{d}\right)
$$

where $\sigma_{0}$ is the elongational yield stress and $\alpha$ and $n_{B B}$ are fitting parameters which depend on the material's behaviour. Cement-based materials are considered to follow the VonMises criterion. Hence, the plastic elongational yield stress is equal to $3^{1 / 2} \tau_{0}$, where $\tau_{0}$ is the shear yield stress. The main limitation of this model (Eq. 1), is that $\alpha$ and $n_{B B}$ are not intrinsic material parameters.

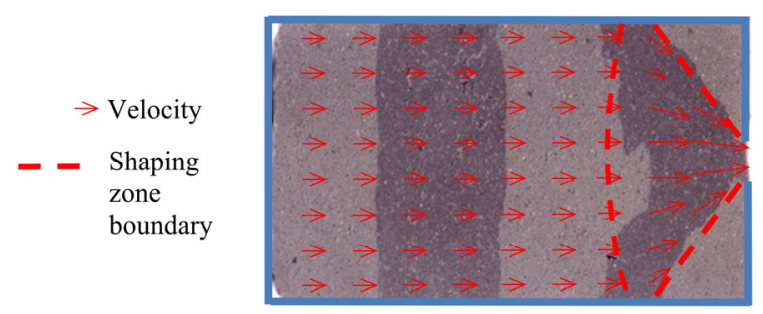

Figure 4. Example of flow profile in the extruder including a localization of the shaping zone

Basterfield et al. [42] have improved the modelling of the shear rate influence on the extrusion force by assuming progressive contraction and neglecting the contribution of shear. Subsequently, Perrot et al. [13] have successfully used this approach to study the rheological behaviour of extrudable cementitious material by adding the contribution of shear on the tapered surface.

\subsection{Flow and friction in the extruder barrel 3.3.1 Case of ram extrusion}

According to numerical studies, the flow profile in the extrusion barrel depends on the Bingham number [38]. Two zones could appear within the material billet: a plug flow zone at the centre of the barrel and a shear zone between the extruder wall and the plug flow zone. The diameter of the plug-flow zone increases with the Bingham number, similar to flow through pipes during pumping. For flows high Bingham numbers, for example the case of material with high yield stress, the entire billet as a plug, as shown in Figure 4.

In such case, the interfacial behaviour is driven by the material tribological behaviour. In relation to the friction occurring at the extruder surface, Perrot et al. [13] have shown that the interfacial shear stress $\tau_{w}$ is a fraction of the bulk shear stress.

\subsubsection{Case of screw extrusion}

The modelling of the screw extrusion flow of visco-plastic materials is difficult due to the complex geometry of the screw. Such flow has only been described in few studies for clay [17, 20, 43] and cement-based materials [44]. Using a 
visco-elastic model, Mu et al. [19] estimated the flow rate during screw extrusion of concrete. Additional investigations are required on the subject of computing the flow rate of the material with the screw's rotational velocity.

Perrot [19] showed that the axial force acting on the screw is equal, as in the case of ram extrusion, to the sum of the shaping force and the frictional force acting on the extruder surface.

In the context of 3D printing, Nerella et al. proposed a strategy to link the extrusion flow rate to the stator rotational velocity using a progressive cavity pump in the context of concrete 3D printing [34]. Interestingly, the authors have shown that due to slippage at the elastomeric stator surface, the relationship between flow rate and rotational velocity is decidedly nonlinear.

\subsubsection{Definition of extrudability: water drainage phenomenon}

The extrudability of a cementitious material with a given extruder implies that 1 ) the load capacity of the extruder is sufficient, 2) the material remains homogeneous during the process, and 3 ) the formed material retains its shape and withstands gravity. The last condition implies that the cement-based material's elongation yield stress is higher than $\rho g h$, with $\rho$ the material density and $h$ the height of the extrudate [45].

The homogeneity condition can be studied from the point of view of soil mechanics [9-11, 46-48]. Perrot et al. [12] considered a competition between the velocity of the extrusion flow with the velocity of water drainage. The drainage criterion based on the Terzaghi consolidation coefficient has been used to predict whether the material will remain homogeneous during extrusion [10, 47]. Such criterion reads:

$$
\frac{t_{e x t}}{H_{d r}{ }^{2} / C_{V}}<0.1
$$

with $t_{\text {ext }}$ the extrusion time, $H_{d r}$ the maximum drainage length, and $C_{v}$ the consolidation coefficient, a function of the material's permeability and compressibility. According to Terzaghi, $H_{d r} / C_{v}$ is the characteristic consolidation time, and therefore Eq. 2 means that the time of extrusion must be an order of magnitude shorter than the consolidation time. However, recently Perrot et al. [10] showed that two materials with the same $H_{d r} / C_{v}$, a cement-based material and a clay-based material, can exhibit different behaviour during extrusion flow. The authors explained this discrepancy by the different impact of water filtration on the material's rheological behaviour. Indeed, extrudable cement-based materials, contrary to the clay-based, present a closely packed granular network very sensitive to water content [49]. Consequently, Perrot et al. [10] have proposed a criterion that takes into account the sensitivity of the rheological behaviour to liquid drainage:

$$
D c=\frac{1}{\tau_{i n i}}\left(\frac{d \tau}{d e}\right)_{i n i} \frac{t}{H^{2} / C_{V}}
$$

where $\tau$ is the shear stress along at the extruder wall, $e$ is the material void ratio (liquid volume / solid volume) and $\tau_{\text {ini }}$ is the initial shear stress before any drainage. Therefore, $(d \tau / d e)_{\text {ini }}$ is the variation of the shear stress at the material/extruder interface at the beginning of the flow. The drainage criterion can be computed using the relationship of shear stress to void ratio.

To describe the rheological behaviour of a cementitious material during extrusion, Khelifi et al. [11] proposed a model based on the evolution of the material behaviour from purely plastic to frictionally plastic. For mineral suspensions such as stiff cement-based materials, instantaneous shear resistance, undrained conditions in soil mechanics, is the combination of three mechanisms:

- intergranular friction which occurs if the solid volume fraction is higher than $0.8 \phi_{m}$ ( $\phi_{m}$ denotes the close packing volume fraction.);

- yield stress; and

- viscous contributions.

Khelifi et al. [11] neglected the third contribution; as a result, the shear stress could be expressed as a simple Coulomb's Law:

$$
\tau=\tau_{0}(e)+\tan \varphi(e) \cdot \sigma_{n}
$$

where $\varphi$ is the internal friction angle and $\sigma_{n}$ is the stress normal to the wall of the extruder.

It is important to note that the authors take an initial value of $\phi$ equal to 0 when the solid volume fraction is lower than $80 \%$ $\phi_{m}$, while between $80 \% \phi_{m}$ and $\phi_{m}$, they use a linear increase of the friction angle to a maximal value of $30^{\circ}$ for cementitious materials and $20^{\circ}$ for clay materials. Perrot et al. [10] noted that the occurrence of friction induces in the extruder an exponential profile of axial stress that accelerates the drainage phenomenon and, therefore, the extrusion load. They also showed that the initial solid volume fraction is closer to the $80 \% \phi_{m}$ for cementitious materials than for claybased materials. This makes cementitious materials more difficult to extrude in comparison to clay-based systems. Thus, viscosity-modifying agents and/or nanoparticles are often used in cement-based mixtures to reduce water drainage.

\section{Specific points related to extrusion 4.1 Flow-induced orientation of fibres}

Extrusion of fibre-reinforced cementitious materials is known to orient the fibres along the direction of extrusion flow. This generally results in the extruded elements' having superior tensile and flexural properties, provided the loading direction is parallel to the fibre orientation. The extrusion-flow-induced orientation of fibres has been observed when producing highperformance, strain-hardening cementitious composites [2, 30], also in 3D-printing [50].

\subsection{Surface defects}

Another important aspect related to extrusion of cementitious materials is the surface quality of the extrudate. Tears and ruptures can appear on the surface of the 
extrudates and are often related to local drainage of water at low extrusion velocity [10] and insufficient early-age tensile strength at high extrusion rates [51]; see Figure 5. The literature on surface defects of extrudates is rich for polymers and plastic materials, but only few studies have dealt with this problem in the context of mineral materials. The authors believe that it is important to study and model accurately the mechanisms of tear and failure formation. Surface roughness and the occurrence of tears and ruptures depend on the paste content, maximum aggregate size, yield-stress, and other features of the cement-based composites. In the case of 3Dprinting the relationship between the material flowrate and printhead velocity influences the surface quality critically as well [34]. Although in conventional extrusion smoother surfaces are strived for, in 3D-printing overly smooth surfaces can negatively influence the layer-to-layer bond strengths.
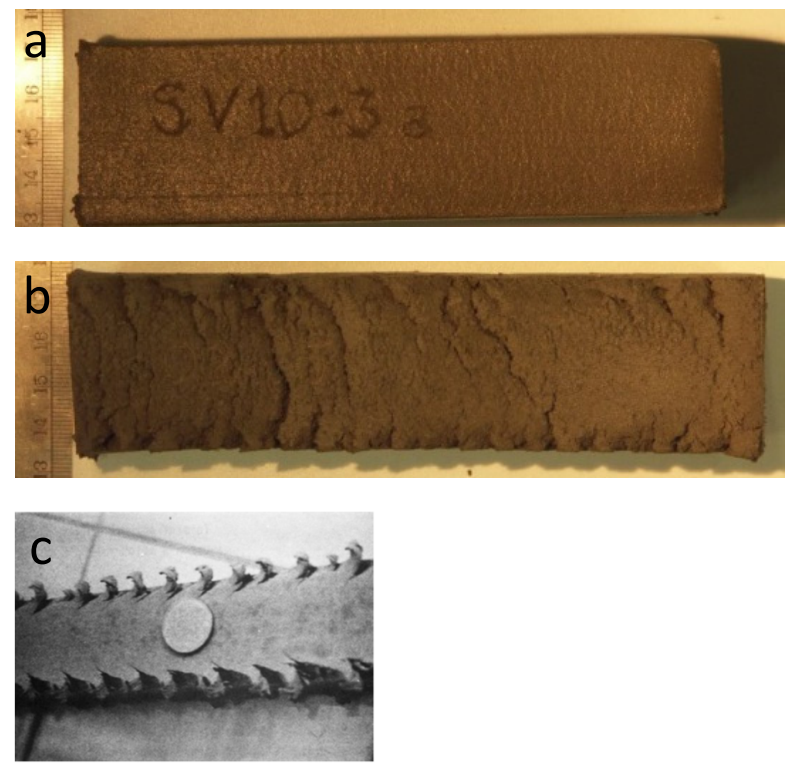

Figure 5. Example of extrudates a) with good surface quality; b) with surface ruptures and; c) tears.

\section{Conclusions}

An overview of the extrusion techniques for cementitious materials is presented, showing various technologies and applications based on extrusion, most prominently recent developments in 3D-concrete-printing. The extrusion flow of the cement-based materials was shown to be composed of the elongational flow near the contraction in the so-called shaping zone driven by the material rheological behaviour and the plug flow in the barrel driven by the tribological behaviour. Flow analyses showed that special attention must be paid to prevent the risk of water drainage that may hinder extrusion flow. Research on drainage and other process hindrances appear to be specifically necessary in the context of 3D-concrete-printing applications.

\section{Bibliography}

[1] P.M McKinnon, Curb forming and extruding apparatus. Washington, DC: U.S. Patent and Trademark Office (1994). U.S. Patent No. $5,354,189$.

[2] VC. Li, On engineered cementitious composites (ECC). J Adv Concr Techn (2003) 1: 215-230. https://doi.org/10.3151/jact.1.215
[3] A. Perrot, D. Rangeard, A. Pierre, Structural built-up of cement-based materials used for 3D-printing extrusion techniques. Mater Struct (2016) 49: 1213-1220. https://doi.org/10.1617/s11527-015-0571-0

[4] T. Wangler, E. Lloret, L Reiter, et al, Digital Concrete: Opportunities and Challenges. RILEM Tech Lett (2016) 1: 67-75. https://doi.org/10.21809/rilemtechlett.2016.16

[5] N. Roussel, Rheological requirements for printable concretes. Cem Concr Res (2018) 112: 76-85. https://doi.org/10.1016/j.cemconres.2018.04.005

[6] RJM. Wolfs, FP. Bos, TAM. Salet, Early age mechanical behaviour of 3D printed concrete: Numerical modelling and experimental testing. Cem Concr Res (2018) 106: 103-116. https://doi.org/10.1016/i.cemconres.2018.02.001

[7] RA. Buswell, W.R Leal de Silva, SZ. Jones, J. Dirrenberger J, 3D printing using concrete extrusion: A roadmap for research. Cem Concr Res (2018) 112: 37-49. https://doi.org/10.1016/i.cemconres.2018.05.006

[8] J. Benbow, J. Bridgewater J, Paste flow and extrusion, Oxford University Press (UkK) (1993).

[9] A. Perrot, D. Rangeard, Y. Mélinge, et al., Extrusion Criterion for Firm Cement-based Materials. App Rheol (2009) 19: 53042. https://dx.doi.org/10.3933/ApplRheol-19-53042

[10] A. Perrot, D. Rangeard, Y. Mélinge, Prediction of the ram extrusion force of cement-based materials. Applied Rheol (2014) 24: 53320. https://dx.doi.org/10.3933/ApplRheol-24-53320

[11] H. Khelifi, A. Perrot, T. Lecompte, et al, Prediction of extrusion load and liquid phase filtration during ram extrusion of high solid volume fraction pastes. Powder Technology (2013) 249: 258-268. https://doi.org/10.1016/j.powtec.2013.08.023

[12] X. Zhou, Z. Li, Characterization of rheology of fresh fiber reinforced cementitious composites through ram extrusion. Mater Struct (2005) 38:17-24. https://doi.org/10.1007/BF02480570

[13] A. Perrot, Y. Mélinge, D. Rangeard, et al, Use of ram extruder as a combined rheo-tribometer to study the behaviour of high yield stress fluids at low strain rate. Rheol Acta (2012) 51: 743-754. https://doi.org/10.1007/s00397-012-0638-6

[14] R. Alfani, GL. Guerrini, Rheological test methods for the characterization of extrudable cement-based materials-a review. Mater Struct (2005) 38: 239-247. https://doi.org/10.1007/BF02479349

[15] KG. Kuder, SP. Shah, Rheology of Extruded Cement-Based Materials. ACI Mater J (2007) 104: 283-290 https://doi.org/10.14359/18674

[16] A. Pierre, A. Perrot, A. Histace, et al., A study on the limitations of a vane rheometer for mineral suspensions using image processing. Rheol Acta (2016) 56: 351-367. https://doi.org/10.1007/s00397-0170993-4

[17] F.Händle, Extrusion in ceramics. Springer Science \& Business Media. (2007) https://doi.org/10.1007/978-3-540-27102-4

[18] R. Alfani, N. Grizzuti, GL. Guerrini, G. Lezzi, The use of the capillary rheometer for the rheological evaluation of extrudable cementbased materials. Rheol Acta (2007) 46: 703-709. https://doi.org/10.1007/s00397-007-0164-0

[19] A. Perrot, Conditions d'extrudabilité des matériaux à base cimentaire. PhD Thesis, Rennes, France, INSA (2006).

[20] AS. Burbidge, J. Bridgwater J, The single screw extrusion of pastes. Chem Eng Sci (1995) 50: 2531-2543. https://doi.org/10.1016/00092509(95)00107-G

[21] HÄNDLE website, accessed February 2019. https://www.haendle.com/haendle/industrien/faserzement/?lang= en

[22] X. Zhou, Z. Li, Manufacturing cement-based materials and building products via extrusion: from laboratory to factory. Proc I Civil Eng Civil Eng (2015) 168: 11-16. https://doi.org/10.1680/cien.14.00065

[23] H. Khelifi, T. Lecompte, A. Perrot, G. Ausias, Mechanical enhancement of cement-stabilized soil by flax fibre reinforcement and extrusion processing. Mater Struct (2016) 49: 1143-1156. https://doi.org/10.1617/s11527-015-0564-z

[24] N. Tregger, M. Pakula, SP. Shah, Influence of micro-and nanoclays on fresh state of concrete. Transp Res Rec (2010) 2141:68-74. https://doi.org/10.3141/2141-12

[25] Y. Shao, J. Qiu, SP. Shah, Microstructure of extruded cement-bonded fiberboard. Cem Concr Res (2001) 31: 1153-1161. https://doi.org/10.1016/S0008-8846(01)00535-X

[26] F. Micaelli, C. Lanos, G. Levita, Rheology and Extrusion of Cement Fly Ashes Pastes. In: AIP Conference Proceedings. AIP, (2008) 1027:665 - 667. https://doi.org/10.1063/1.2964801 
[27] Y. Mélinge, VH. Hoang, D. Rangeard, et al., Study of tribological behaviour of fresh mortar against a rigid plane wall. Eur J Environ Civ Eng (2013) 17:419-429. https://doi.org/10.1080/19648189.2013.786242

[28] FX. Mortreuil, C. Lanos, C. Casandjian, M. Laquerbe, Utilisation des propriétés électriques des pâtes céramiques pour leur extrusion. Industrie Céramique et Verrière (2000) 88-95.

[29] A. Perrot, Y. Mélinge, P. Estellé, C. Lanos, Vibro-extrusion: A new forming process for cement-based materials. Adv Cem Res (2009) 21: 125-133. https://doi.org/10.1680/adcr.2008.00030

[30] H. Stang, VC. Li, Extrusion of ECC-material. In: Proceedings of High Performance Fibre Reinforced Cement Composites. (1999) 3: 203212.

[31] X. Qian, X. Zhou, B. Mu, Z. Li, Fibre alignment and property direction dependency of FRC extrudate. Cem Concr Res (2003) 33: 1575-1581. https://doi.org/10.1016/S0008-8846(03)00108-X

[32] VC. Li, S. Wang, C. Wu, Tensile strain-hardening behaviour of polyvinyl alcohol engineered cementitious composite (PVA-ECC). ACI Mater J (2001) 98:483-492. https://doi.org/10.14359/10851

[33] VN. Nerella, M. Krause, M. Näther, V. Mechtcherine, Studying printability of fresh concrete for formwork free Concrete on-site 3D Printing technology technology (CONPrint3D). In: Kusterle W, Teubert O, Greim M (eds) Rheologische Messungen an Baustoffen. Tredition GmbH, Hamburg, Regensburg (2016) 236-246.

[34] VN. Nerella, M. Näther, A. Iqbal et al, Inline quantification of extrudability of cementitious materials for digital construction. Cem Concr Compos (2019) 95: 260-270. https://doi.org/10.1016/j.cemconcomp.2018.09.015

[35] A. Perrot, C. Lanos, Y. Melinge, P. Estellé, Mortar physical properties evolution in extrusion flow. Rheol Acta (2007) 46: 1065-1073. https://doi.org/10.1007/s00397-007-0195-6

[36] BD. Rabideau, P. Moucheront, F. Bertrand, et al, The extrusion of a model yield stress fluid imaged by MRI velocimetry. J Nonnewton Fluid Mech (2010) 165: 394-408. https://doi.org/10.1016/j.jnnfm.2010.01.015

[37] BD. Rabideau, P. Moucheront, F. Bertrand, et al., Internal flow characteristics of a plastic kaolin suspension during extrusion. J Am Ceram Soc (2012) 95: 494-501. https://doi.org/10.1111/j.15512916.2011.04882.x

[38] P. Jay, A. Magnin, JM. Piau, Numerical simulation of viscoplastic fluid flows through an axisymmetric contraction. J Fluids Eng (2002) 124: 700-705. https://doi.org/10.1115/1.1486472

[39] PR. de Souza Mendes, MF. Naccache, PR. Varges, FH. Marchesini, Flow of viscoplastic liquids through axisymmetric expansionscontractions. J Nonnewton Fluid Mech (2007) 142: 207-217. https://doi.org/10.1016/i.jnnfm.2006.09.007

[40] DJ. Horrobin, Theoretical aspects of paste extrusion. PhD. Thesis, University of Cambridge, UK (1999).

[41] X. Zhou, Z. Li, M. Fan, H. Chen, Rheology of semi-solid fresh cement pastes and mortars in orifice extrusion. Cem Concr Compos (2013) 37: 304-311. https://doi.org/10.1016/j.cemconcomp.2013.01.004

[42] RA. Basterfield, CJ. Lawrence, MJ. Adams, On the interpretation of orifice extrusion data for viscoplastic materials. Chem Eng Sci (2005) 60:2599-2607. https://doi.org/10.1016/i.ces.2004.12.019

[43] JF. Carley, RS. Mallouk, JM. McKelvey Simplified flow theory for screw extruders. Ind Eng Chem (1953) 45: 974-978. https://doi.org/10.1021/ie50521a032

[44] B. M, Z. Li, SNC. Chui, J. Peng, Cementitious composite manufactured by extrusion technique. Cem Concr Res (1999) 29: 237-240. https://doi.org/10.1016/S0008-8846(98)00097-0

[45] N. Roussel, P. Coussot, "Fifty-cent rheometer" for yield stress measurements: From slump to spreading flow. J Rheol (2005) 49: 705. https://doi.org/10.1122/1.1879041

[46] Z. Toutou, N. Roussel, C. Lanos, The squeezing test: A tool to identify firm cement-based material's rheological behaviour and evaluate their extrusion ability. Cem Concr Res (2005) 35: 1891-1899. https://doi.org/10.1016/j.cemconres.2004.09.007

[47] PJ. Martin, DI. Wilson, PE. Bonnett, Paste extrusion through nonaxisymmetric geometries: Insights gained by application of a liquid phase drainage criterion. Powder Technology (2006) 168: 64-73. https://doi.org/10.1016/i.powtec.2006.06.018

[48] S. Mascia, MJ. Patel, SL. Rough, et al, Liquid phase migration in the extrusion and squeezing of microcrystalline cellulose pastes. Eur J Pharm Sci (2006) 29: 22-34. https://doi.org/10.1016/i.ejps.2006.04.011
[49] J. Yammine, M. Chaouche, M. Guerinet, et al, From ordinary rhelogy concrete to self-compacting concrete: A transition between frictional and hydrodynamic interactions. Cem Concr Res (2008) 38: 890-896. https://doi.org/10.1016/j.cemconres.2008.03.011

[50] H. Ogura, VN. Nerella, V. Mechtcherine, Developing and Testing of Strain-Hardening Cement-Based Composites (SHCC) in the Context of 3D-Printing. Materials (2018) 11: 1375. https://doi.org/10.3390/ma11081375

[51] OL. Kulikov, K. Hornung, Wall detachment and high rate surface defects during extrusion of clay. J Nonnewton Fluid Mech (2002) 107: 133-144. https://doi.org/10.1016/S0377-0257(02)00145-3 